\title{
Markov Chains: \\ Reintroducing Lost Knowledge Back into a Modeling and Simulation Course
}

\author{
Kathleen M. Kaplan, D.Sc., Lt Col John J. Kaplan (Ph.D., J.D.) USAF \\ Howard University/USAF
}

\begin{abstract}
"Over 500 educational institutions are using Arena today!" states the popular textbook site. Many of these educational institutions use the Arena textbook in their Modeling and Simulation $(M \& S)$ courses. Yet, out of this six hundred sixty eight page M\&S book, only one sentence mentions "Markovian." Compare this to a textbook used by the authors in their college years, an entire section is dedicated to "Markov Chains and Their Properties" and Markovian techniques are seen throughout this earlier textbook. While the authors may be dinosaurs clinging to the past, the importance of integrating Markov Chains into an M\&S course cannot be overlooked. In fact, there are at least nine simulation programs in use that are based on Markov principles: CARE III (Computer Aided Reliability Estimation), CARE RBD Markov Model, CARMS (Computer-Aided Rate Modeling and Simulation), CARSA (Computer Aided Redundant System Reliability Analysis), MARKOV1 (Decision Systems Associates), MKV, PC Availability (Markov), RAP (Reliability and Availability Program), and SURE (Semi-Markov Unreliability Range Evaluator). While the programmers of these simulation tools understand Markov principles, they did not receive that information from the popular Arena textbook! Instruction based solely upon the Arena text has lost the knowledge of Markov. Obviously there is interest in the use of Markov principles, so why aren't these principles included in engineering instruction? The popular textbook uses application software, which is a favorable teaching tool, but cannot be relied upon fully as the programs do not allow students to completely understand and appreciate this important underlying concept of M\&S. M\&S educators should ensure this lost knowledge of Markov principles is reintroduced back into the M\&S classroom.
\end{abstract}

This paper will discuss the current educational trend in M\&S and provide ways to incorporate Markov Chains and principles into the curriculum. In combining both a computer application program and Markovian techniques, the student will be able to fully appreciate the connection of mathematics and engineering, required in all ABET accredited programs.

"Proceedings of the 2005 American Society for Engineering Education Annual Conference \& Exposition Copyright (C2005, American Society for Engineering Education" 


\section{Introduction}

Modeling and Simulation (M\&S) is an important upper level undergraduate course in many engineering disciplines. Due to its placement as a junior or senior level course, there is an assumption that primary engineering education is necessary to comprehend and apply its content. One would not have this idea by reading a popular textbook. Most undergraduate engineering students are only being exposed to application, point-and-click, software. Underlying concepts, especially mathematical concepts, are not being applied in many M\&S courses. Without this reinforcement of basic engineering utilities, the student feels a disconnect with what is required, such as calculus, and the art itself, such as modeling and simulation. Needless to say, ABET requirements are not satisfied by the popular point-and-click method of teaching M\&S. Therefore, other approaches must be the incorporated into M\&S courses.

Discussions of M\&S, Markov Chains, and the current educational trend in M\&S follow. Also, the paper includes suggested of ways to incorporate the use of Markov Chains into the teaching of M\&S, and a specific example. The first topic discussed is the most important: the relevance of incorporating Markov Chains into an M\&S course.

\section{Relevance}

Prior to discussing of incorporating Markov Chains into Modeling and Simulation (M\&S) courses, proof of its importance must be given. This proof includes the importance in research as well as ABET accreditation.

\subsection{Importance in Research}

Obviously, M\&S is a vital research area. The United States Department of Defense (DoD) has at least four offices dedicated to M\&S: (1) The Air Force Agency for Modeling and Simulation $\left(\right.$ AFAMS) ${ }^{1}$; (2) The U.S. Department of Defense Modeling and Simulation Office ${ }^{2}$; (3) The U.S. Army Model and Simulation Office (AMSO), and; (4) The U.S. Navy Air Defense Threat Simulation \& Validation Office ${ }^{3}$. Specifically, Markov Chains has been discussed in many government documents and research ${ }^{4,5}$. It is also taught in the Air Force Institute of Technology (AFIT) course, OPER 540 - Stochastic Modeling and Analysis I ${ }^{6}$.

A quantitative measure of research can be obtained by examining the numbers of patents and pending patent applications ${ }^{7}$. From 1978 until the present, there have been 226 patents granted utilizing the key term, "Markov Chain." Currently, there are, using the same search term, 219 patent applications pending. Reviewing the years of issue, in 1978 there was 1 patent granted; 0 in years 1979 to 1982; in 1983 and 1984, there was 1 patent granted each year; in 1985, 0; in 1986,5 ; in 1987,0 ; in 1988, 3; in 1989, 1; in 1990, 5; 3 in each year 1991 and 1992; in 1993, 4; in 1994,10 ; in 1995,8 ; in 1996, 16; in 1997; 16; in 1998, 19; in 1999, 12; in 2000, 21; in 2001, 18; in 2002, 22; in 2003, 26; in 2004, 31. The trend can be seen in Fig. 1. 


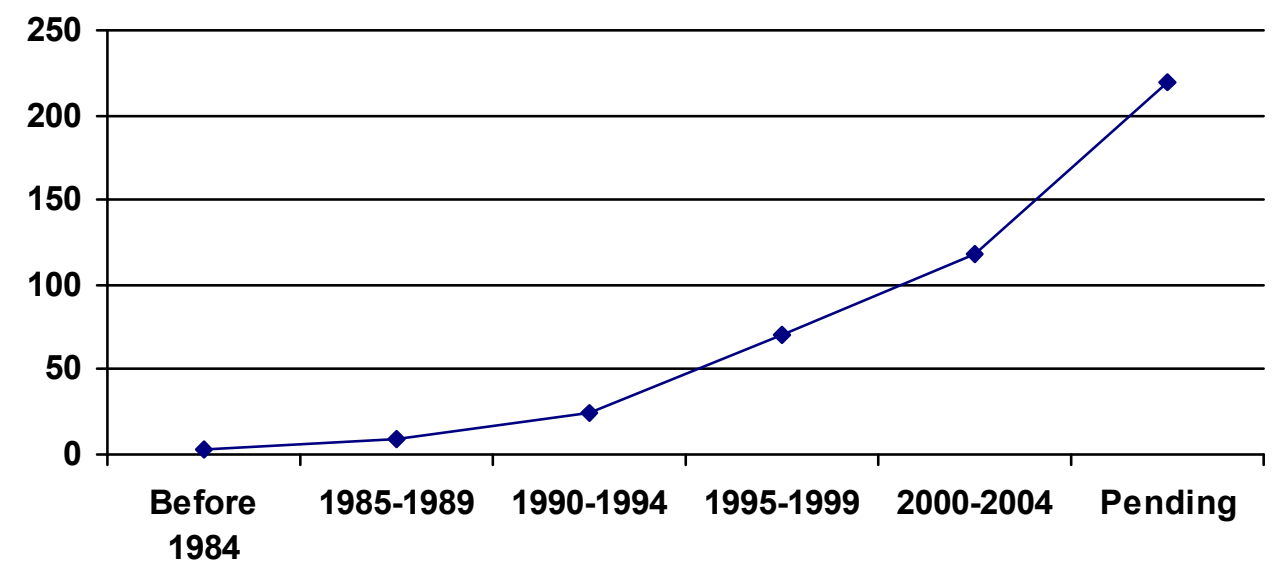

Figure 1. Markov Chain Patents and Applications

Note that the research interest in Markov Chains is not decreasing; it is increasing exponentially! Educators must keep up with the trend.

\subsection{Importance in ABET Accreditation}

Teaching Markov Chains in M\&S follows the guidelines specified by the Accreditation Board Engineering Technology (ABET). In the ABET 2004-2005 criteria for "Accrediting Engineering Programs," the "Program Criteria for Electrical, Computer, and Similarly Named Engineering Programs" section states in "Criterion 3. Program Outcomes and Assessment" specifically that "Engineering programs must demonstrate that their graduates have: (a) an ability to apply knowledge of mathematics, science, and engineering; (b) an ability to design and conduct experiments, as well as to analyze and interpret data; (c) an ability to design a system, component, or process to meet desired needs; ... (e) an ability to identify, formulate, and solve engineering problems; ... (k) an ability to use the techniques, skills, and modern engineering tools necessary for engineering practice." And most specific disciplines require a "proficiency in mathematics" 8 .

Therefore, Markov Chains is important not only in current research, but also follows ABET guidelines.

\section{Modeling and Simulation (M\&S)}

Modeling and Simulation (M\&S) allows engineers to study a real-world event without experimenting on the actual event. Modeling is the research part where the event is studied and a representation is formalized; simulation builds upon the model and creates an implementation with respect to time over the given event. By using modeling and simulation, important data can be obtained that would be a basis for making managerial or technical decisions 9 . Typical examples of modeling and simulation are aircraft flight simulators or electronic circuit simulators, and a specific example of a Markov Chain M\&S project is weapon's system and software evaluation ${ }^{10}$. 


\section{Markov Chains}

$\mathrm{M} \& \mathrm{~S}$ is based upon many concepts that freshmen and sophomore engineers learn including probability and queuing theory. Markov Chains should be taught in probability theory courses, but in case it is not, it must be introduced at some time in the engineer's undergraduate program. In any case, Markov Chains should be used in M\&S courses.

\subsection{Markov Chains 101}

The Markovian property is the probability that any future state of a system, given the past and present states, is independent of the past events and depends only on the present state of the process.

Suppose there is a random sequence, $\mathrm{X}$, such that:

$$
\mathrm{X}=\{\mathrm{a}, \mathrm{b}, \ldots, \mathrm{N}\}
$$

This set corresponds to a time interval set based on the interval, $[0, t]$.

$$
\begin{aligned}
& \mathrm{X}=\left\{\begin{array}{cccc}
\mathrm{a}, & \mathrm{b}, & \ldots, & \mathrm{N} \\
\downarrow & \downarrow & & \downarrow
\end{array}\right\} \\
& \mathrm{t}=\{\quad 0, \quad 1, \quad \ldots, \quad \mathrm{t}\} \text {. }
\end{aligned}
$$

Thus, each element of set $X$ corresponds to a unique element of set $t$. This can be written as the set of $X$ given subscripts in the set of $t$,

$$
\begin{gathered}
\mathrm{X}_{\mathrm{t}=0}=\mathrm{X}_{0}=\mathrm{a} \\
\mathrm{X}_{\mathrm{t}=1}=\mathrm{X}_{1}=\mathrm{b} \\
\vdots \\
\mathrm{X}_{\mathrm{t}=\mathrm{t}}=\mathrm{X}_{\mathrm{t}}=\mathrm{N} .
\end{gathered}
$$

Note: The values that $\mathrm{X}_{\mathrm{t}}$ take on are finite or countably infinite. Then, the Markov Chain Property is:

$$
P\left[X_{t-1}=j \mid X_{0}=a, X_{1}=b, \ldots, X_{t}=i\right]=P\left[X_{t-1}=j \mid X_{t}=i\right]=q_{i j}(t) .
$$

This is the conditional probability that the Markov Chain is at time $t$ in state $j$, given that at time $(t-1)$ it was in state $i$. The end result, $q_{i j}(t)$, is also called the transition probability.

This means that the probability of a future state, given the past and present states, is independent of the past events and depends only on the present state of the probability, $p_{j}(t+1)$, which represents the random value $\mathrm{X}_{\mathrm{t}+1}$ takes on in state $j$. 


$$
\begin{aligned}
& p_{j}(t+1)=\sum_{i=1}^{N} p_{i}(t) \cdot q_{i j}(t), \text { for } j=1,2, \ldots, N \\
& \underbrace{p_{j}(t+1)}_{\begin{array}{c}
\text { Prob. you're } \\
\text { in state } \mathrm{j} \\
\text { at time } \mathrm{t}+\mathrm{t}
\end{array}}=\underbrace{\sum_{i=1}^{N}}_{\begin{array}{c}
\text { Sum of } \\
\text { the }
\end{array}} \underbrace{p_{i}(t)}_{\begin{array}{c}
\text { prob. in } \\
\text { state iat } \\
\text { time } \mathrm{t}
\end{array}} \cdot \underbrace{q_{i j}(t)}_{\begin{array}{c}
\text { taking the } \\
\text { transition ij } \\
\text { at time } \mathrm{t}
\end{array}}
\end{aligned}
$$

Or, in matrix and vector representation,

where:

$$
\mathrm{p}(\mathrm{t}+1)=\mathrm{p}(\mathrm{t}) \mathrm{Q}(\mathrm{t})
$$

$p(t)$ is an $\mathrm{N}$-dimensional row vector with elements $p_{j}(t)$, for $j=1,2, \ldots, N$

$\mathrm{Q}(\mathrm{t})$ is an $\mathrm{N} x \mathrm{~N}$ matrix with the elements $\mathrm{q}_{\mathrm{ij}}(\mathrm{t})$ and is called the Markov transition probability matrix at time $t$.

\subsection{Stationary or Homogeneous}

If all $q_{i j}(t)$ are independent of time $t$, then:

$$
p(t+1)=p(t) Q .
$$

$\mathrm{Q}$ and $\mathrm{Q}(\mathrm{t})$ must follow the properties:

1. $\mathrm{q}_{\mathrm{ijj}}(\mathrm{t}) \geq 0$, for all $\mathrm{i}, \mathrm{j}$ and $\mathrm{t}=0,1,2, \ldots$

2. $\sum_{j=1}^{N} q_{i j}(t)=1$, for all $\mathrm{i}$ and $\mathrm{t}=0,1,2, \ldots$ 


\subsubsection{Example: Stationary System}

A way to incorporate Markov Chains into a $M \& S$ course is to require the student to determine if a system is stationary. This exercise is simple and only requires a state transition diagram. The student must identify if the diagram is homogenous by verifying that it fulfills the requirements.

Given the following state transition diagram, find if it corresponds to a stationary Markov Chain.

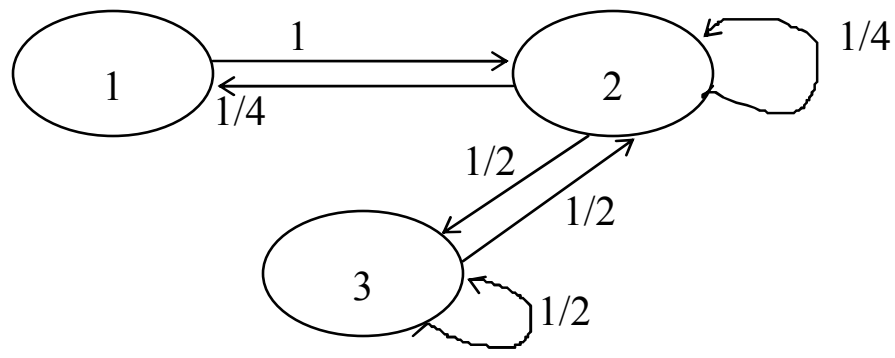

Figure 2. State Transition Diagram

The states are in the set $\{1,2,3\}$, with transitions:

$$
\mathrm{q}_{12}=1, \mathrm{q}_{23}=1 / 2, \mathrm{q}_{33}=1 / 2, \mathrm{q}_{32}=1 / 2, \mathrm{q}_{22}=1 / 4, \mathrm{q}_{21}=1 / 4
$$

In matrix form this is:

$$
\begin{aligned}
& \mathrm{Q}=\left|\begin{array}{lll}
\mathrm{q}_{11} & \mathrm{q}_{12} & \mathrm{q}_{13} \\
\mathrm{q}_{21} & \mathrm{q}_{22} & \mathrm{q}_{23} \\
\mathrm{q}_{31} & \mathrm{q}_{32} & \mathrm{q}_{33}
\end{array}\right| \\
& \mathrm{Q}=\left|\begin{array}{lll}
0 & 1 & 0 \\
1 / 4 & 1 / 4 & 1 / 2 \\
0 & 1 / 2 & 1 / 2
\end{array}\right|
\end{aligned}
$$

Does $\mathrm{Q}$ follow the following properties?

1. $\mathrm{q}_{\mathrm{ijj}}(\mathrm{t}) \geq 0$, for all $\mathrm{i}, \mathrm{j}$ and $\mathrm{t}=0,1,2, \ldots$

2. $\sum_{j=1}^{N} q_{i j}(t)=1$, for all $i$ and $\mathrm{t}=0,1,2, \ldots$

Property 1 requires that every element in $\mathrm{Q}$ be greater or equal to zero, which is true. Property 2 requires that every row sum to one, which is also true. Therefore, the system represented by the state transition diagram is homogeneous, or stationary.

\subsection{Stationary Distribution}

Markov Chains are interesting in that they may converge to some limiting distribution, or stationary distribution. In order to find a stationary distribution, the Markov chain must be aperiodic and ergodic. 
Assume an aperiodic, irreducible system is stable. Let,

$$
\lim _{t \rightarrow \infty} p(t)=\pi
$$

Then,

$$
\begin{gathered}
\mathrm{p}(\mathrm{t}+1)=\mathrm{p}(\mathrm{t}) \mathrm{Q} \\
\pi=\pi \mathrm{Q}
\end{gathered}
$$

A probability distribution $\pi$ satisfying this equation is called a stationary distribution.

An irreducible aperiodic Markov Chain has:

- At most one stationary distribution

- And either

1. All states are transient or all are null, so there's no stationary distribution.

$$
\lim _{t \rightarrow \infty} q_{i j}^{(n)}=0
$$

2. All states are ergodic, so there's a unique stationary distribution.

$$
\lim _{t \rightarrow \infty} q_{i j}^{(n)}=\pi_{i j}
$$

\subsubsection{Example: Stationary Distribution}

A further way to incorporate Markov Chains into a M\&S course is to require the student to determine if a system has a stationary distribution, or, in other words, it obtains some steady state. This exercise is also simple. The student must identify that the system is aperiodic and ergodic, and if true, perform some simple algebra to find the stationary distribution.

Given the state diagram above that corresponds to a system. Obviously, this state diagram is aperiodic and ergodic (all states are reachable). Therefore, a stationary distribution can be found.

Since $\pi$ is the probability of being in any state at the end of time, time $\infty$,

$$
\pi=1
$$

Also, since $\pi$ is the sum of the probabilities of being in any of the states,

$$
\pi=\pi_{1}+\pi_{2}+\pi_{3}=1
$$

Where $\pi_{1}$ is the probability of being in state $1, \pi_{2}$ is the probability of being in state 2 , and $\pi_{3}$ is the probability of being in state 3 , each at the end of time. These probabilities are found by reviewing the Q matrix. Each column in matrix Q gives the probability of being in a given state. Thus, 


$$
\begin{aligned}
& \pi_{1}=0 \cdot \pi_{1}+\frac{1}{4} \cdot \pi_{2}+0 \cdot \pi_{3}=\frac{1}{4} \cdot \pi_{2} . \\
& \pi_{2}=1 \cdot \pi_{1}+\frac{1}{4} \cdot \pi_{2}+\frac{1}{2} \cdot \pi_{3} \Rightarrow \frac{3}{4} \cdot \pi_{2}=\pi_{1}+\frac{1}{2} \cdot \pi_{3} . \\
& \pi_{3}=0 \cdot \pi_{1}+\frac{1}{2} \cdot \pi_{2}+\frac{1}{2} \cdot \pi_{3} \Rightarrow \frac{1}{2} \cdot \pi_{3}=\frac{1}{2} \cdot \pi_{2} \Rightarrow \pi_{3}=\pi_{2} .
\end{aligned}
$$

Writing the equation above in terms of $\pi_{2}, \pi_{2}$ can be obtained.

$$
\begin{aligned}
& \frac{1}{4} \cdot \pi_{2}+\pi_{2}+\pi_{2}=1 . \\
& \pi_{2}=\frac{4}{9} .
\end{aligned}
$$

From this, the other values are found:

$$
\begin{aligned}
& \pi_{1}=\frac{1}{4} \cdot \pi_{2}=\frac{1}{4} \cdot \frac{4}{9}=\frac{1}{9} . \\
& \pi_{3}=\pi_{2}=\frac{4}{9} .
\end{aligned}
$$

Thus, the stationary distribution is:

$$
\pi=\left[\begin{array}{lll}
\frac{1}{9} & \frac{4}{9} & \frac{4}{9}
\end{array}\right]
$$

\subsection{Markov Chains - Other Uses}

Markov Chains can be used in other ways, and there are many more difficult problems that can be investigated using Markov Chains. These other methods can be introduced in extended work, or graduate studies. Yet, without an introduction to Markov Chains in an engineer's undergraduate curriculum, the basics given in this paper will not be known to allow for future study.

\section{Markov Chains in Modeling and Simulation}

Modeling and Simulation (M\&S) is concerned with systems. These systems can be discrete, such as a bank model, or continuous, such as a water flow process. Markov Chains can be used to model either type of system, and applied at any time during the M\&S process. It is especially useful in determining the steady state of the system, which is indicated by finding the stationary distribution.

\section{Current State of M\&S Courses}

Using a popular textbook as an indication of Markov Chains being introduced into M\&S courses, it can be stated that this subject is not being taught. A popular textbook is Simulation with Arena, as evident by the Arena website statement, "Over 500 educational institutions are using Arena today!"11. It must be noted though that the authors' institution, Howard University (HU), is one of the 500 indicated that use Arena for its M\&S course. Unfortunately, out of this six hundred sixty eight page M\&S book, only one sentence mentions "Markovian." It is doubtful that engineering students will recognize the importance of Markov Chains given this introduction! 
In comparison, a textbook used by the authors in their college years has an entire section dedicated to "Markov Chains and Their Properties" and Markovian techniques are seen throughout this earlier textbook ${ }^{12}$. While the authors may be dinosaurs clinging to the past, the importance of integrating Markov Chains into an M\&S course has already been stressed. We have discussed nine simulation programs in use that are based on Markov principles, government offices using Markov Chains, and the rise in patents using Markov Chains. Obviously there continues to be an interest in the use of Markov principles, yet these principles are not included in engineering instruction via this popular textbook, among others. M\&S educators should ensure this lost knowledge of Markov principles is reintroduced back into the M\&S classroom.

\section{Conclusion}

This paper has shown that Modeling and Simulation (M\&S) is an important topic, as evident by the Department of Defense's many offices. It has also been shown that an important part of $\mathrm{M} \& \mathrm{~S}$ is Markov Chains, as evident by the programs using the technique and the exponential rise in patents referencing Markovian principles. Discussions of M\&S, its relevance, ABET accreditation, and Markov Chains have also been presented. Simple ways to incorporate Markov Chains in a M\&S course have also been presented through two examples.

It has also been presented that in current $M \& S$ courses, most undergraduate engineering students are not being introduced to Markov Chains, as evident by the one-sentence discussion in a popular textbook.

M\&S educators must not rely merely on the point-and-click technology of current Modeling and Simulation textbooks. Engineering students must be able to design M\&S applications, not just use M\&S software. The current application software is useful, but does not address all the underlying concepts important in $\mathrm{M} \& \mathrm{~S}$; it must be combined M\&S techniques, including Markov Chains. We must produce students who are engineers of technology, not merely users of technology.

\footnotetext{
${ }^{1}$ United States Air Force Agency for Modeling and Simulation (AFAMS), http://www.msiac.dmso.mil/mscalendar/default.asp?fctn=orgdetails\&orgid=147, accessed Dec. 2004.

${ }^{2}$ United States Department of Defense, Defense Modeling and Simulation Office, https:/www.dmso.mil/public/, accessed Dec. 2004.

${ }^{3}$ United States Navy, Navy Air Defense Threat Simulation \& Validation Office, DoD 5000.61 DoD Modeling and Simulation (M\&S) Verification, Validation, and Accreditation (VV\&A), http://www.ailtso.com/simval/Documents/5000.61/dod5000.61.htm, accessed Dec. 2004.

${ }^{4}$ Department of Defense Information Analysis Center (IAC), The Reliability Analysis Center, "The Application of Markov Analysis Methods to Reliability, Maintainability, and Safety,” vol. 10, no. 2, 2003, http://rac.alionscience.com/pdf/MARKOV.pdf, accessed Dec. 2004.

${ }^{5}$ U.S. Army Engineer Research and Development Center, "Groundwater Modeling System, Version 4.0 - Features," http://chl.wes.army.mil/software/gms/tprogs.htm, accessed Dec. 2004.
} 
${ }^{6}$ Air Force Institute of Technology, Department of Operational Sciences, Courses in Operations Research, http://en.afit.edu/ens/courses/orcourses.htm, accessed Dec. 2004.

${ }^{7}$ United States Patent and Trademark Office (USPTO), http://www.uspto.gov, research performed Dec. 8, 2004.

${ }^{8}$ Accreditation Board Engineering Technology (ABET), "Criteria for Accrediting Engineering Programs, Effective for Evaluations During the 2004-2005 Cycle," approved Nov. 1, 2003, http://www.abet.org/images/Criteria/E001\%2004-05\%20EAC\%20Criteria\%2011-20-03.pdf, accessed Dec. 2004.

${ }^{9}$ Kaplan, Kathleen, et. al., "Mathematical Induction: The Basis Step of Verification and Validation in a Modeling and Simulation Course," Proceedings of the 2004 American Society for Engineering Education Annual Conference \& Exposition, 2004.

${ }^{10}$ Department of Defense, "DoD Software Collaborators' Workshop - June 30,1999,"

http://www.dacs.dtic.mil/topics/where2go/tacom.html, accessed Dec. 2004.

${ }_{11}$ Arena website, http://www.arenasimulation.com, accessed Dec. 2004.

${ }^{12}$ Kobayashi, H., Modeling and Analysis: An Introduction to System Performance Evaluation Methodology, Addison-Wesley Publishing Company, 1981.

\section{Biographical Information}

\section{KATHLEEN M. KAPLAN, D.Sc.}

Dr. Kaplan is an Assistant Professor in the Department of Systems \& Computer Science at Howard University in Washington, DC. She is also a Registered Patent Agent licensed to practice before the United States Patent and Trademark Office. Dr. Kaplan can be reached at kkaplan@howard.edu, http://www.imappl.org/ kaplan.

JOHN J. KAPLAN, Ph.D., J.D.

Dr. Kaplan is a Lieutenant Colonel ( $\mathrm{Lt} \mathrm{Col}$ ) in the United States Air Force and a Patent Attorney. Lt Col Kaplan is the Deputy Director of Policy and Integration at the Air Force Office of Scientific Research (AFOSR) in Arlington, Virginia. He can be reached at john.kaplan@afosr.af.mil. 